\title{
Recepción de la música eclesiástica de Joseph Haydn en los archivos catedralicios de la Comunidad Valenciana: sus fuentes
}

\author{
Autor: Dr. José Aparisi Aparisi. \\ Director: Dr. Antonio Ezquerro Esteban. \\ Institución: Universidad Politécnica de Valencia. \\ Tribunal: Dr. Luis Antonio González Marín, Dra. Matilde Olarte Martínez (Universidad \\ de Salamanca) y Dr. Juan Carlos Montoya Rubio (Universidad de Murcia).
}

Calificación: Sobresaliente cum laude.

Fecha de defensa: 12 de diciembre de 2015.

Resumen:

Hasta la fecha, no se ha realizado estudio alguno sobre la recepción de la música, particularmente en lo referido al repertorio litúrgico —en latín — de Joseph Haydn, en los principales centros de producción musical eclesiástica de la Comunidad Valenciana. La primera fuente con música de Haydn datada en Valencia, en 1789, en plena actividad compositiva del músico de Rohrau —la parte para el órgano de la "Grosse Orgelsolomesse" (“Gran Misa para solo de órgano”) —, aparece en Valencia sólo tres años después de la composición de Die sieben letžten Worte unseres Erlösers am Kreuze ("Las siete últimas palabras de nuestro Salvador en la Cruz"), fruto del encargo que hiciera la Hermandad de la Santa Cueva de Cádiz al compositor. Por lo demás, el número de atribuciones de composiciones, equivocadamente adjudicadas a Joseph Haydn es, seguramente en el campo de la música de iglesia, mucho mayor que en otros géneros, lo que ofrece un amplio e interesante campo sobre el cual poder investigar.

En definitiva, este trabajo aporta el conocimiento de nuevas fuentes, hasta hoy desconocidas para la investigación internacional, colocando por primera vez a España, y más concretamente, a Valencia, en la escena y foco de interés de la investigación sobre el clasicismo musical. Buena parte de las obras estudiadas, datadas en vida del compositor, o que se ejecutaron en Valencia en vida del compositor — la copia más antigua de la Gran Misa 


\section{TESIS DOCTORALES}

para solo de órgano, de 1789, llega a Valencia sólo tres años después de la composición de Las siete últimas palabras de nuestro Salvador en la Cruz, fruto del encargo que le hiciera la Hermandad de la Santa Cueva de Cádiz al compositor, lo que da buena muestra de una tempranísima recepción de su música -

Se ha podido constatar, en cambio, que ésta y otras varias obras no habían trascendido a centros tan importantes como el Joseph Haydn-Institut de Colonia, donde no se tenía noticia de esas fuentes valencianas. Se ha podido, además, identificar algunos anónimos, así como descubrir y datar ediciones conservadas en Valencia, levantar obras espurias (erróneamente adjudicadas a Joseph Haydn), etc., dando un paso más allá en el trabajo riguroso y científico a propósito de la obra de Joseph Haydn en Valencia. A partir de ahora, la obra del maestro vienés, Haydn, y su impacto o presencia en Valencia, y por extensión, en España, es un poco mejor conocida, y no sólo en España —que también-, sino muy particularmente, en el exterior, pudiendo servir el modelo valenciano para el desarrollo, elaboración y estudio de otros posibles casos peninsulares y latinoamericanos en la importancia de la recepción de la música de Joseph Haydn, entendido como reivindicación de la importancia hispánica para la comprensión de la música de los clásicos vieneses a nivel internacional.

\section{Índice de la tesis:}

\section{Introducción}

Razones para la elección del tema (históricas, sociológicas, geográficas...)

Objetivos del trabajo

Metodología

Agradecimientos

Capitulo 1: Personalidad y trayectoria de Joseph Haydn (resumen crítico).

Capitulo 2: Europa en tiempos de Joseph Haydn (contextos histórico y político, social y económico, cultural y artístico, musical...):

Europa

España

Reino de Valencia

Capitulo 3: Recepción histórica de la música eclesiástica de Joseph Haydn en los archivos musicales catedralicios de la Comunidad Valenciana. 


\section{TESIS DOCTORALES}

Capitulo 4: Análisis crítico de las partituras objeto de estudio, y comentario a las mismas (concreción músico-práctica de su recepción en Valencia — conclusiones-): [con detección de posibles errores y/o malentendidos y propuesta de soluciones]

1. DOMINE DEUS SALUTIS MEAE

2. CUARTETOS op. 17

3. MISA EN MI BEMOL MAYOR, EN HONOR DE LA SANTISIMA VIRGEN MARIA «GRAN MISA PARA SOLO DE ORGANO»

4. STABAT MATER

5. O JESU, TE INVOCAMUS

6. SALVE REGINA

7. ENS AETERNUM, ATTENDE VOTIS

8. MISA BREVE A SAN JUAN DE DIOS «PEQUEÑA MISA PARA SOLO DE ORGANO»

9. MISA CELLENSIS, COMPUESTA PARA EL SEÑOR LIEBE DE KREUTZNER «MISA DE MARIAZELL»

10. LAS SIETE ULTIMAS PALABRAS DE NUESTRO SALVADOR EN LA CRUZ

11. MISA EN TIEMPOS DE GUERRA «MISA DEL TIMBAL»

12. AVE MARIA

13. INSANAE ET VANAE CURAE

14. MISA EN TIEMPOS DE MIEDO Y NECESIDAD «MISA NELSON»

15. TE DEUM PARA LA EMPERATRIZ MARIA TERESA

16. MISA DE LA CREACION

17. SANCTA MARIA

18. AVE, VERUM CORPUS

19. SANCTUS Y BENEDICTUS EXTRAIDO DE LA $10^{\mathrm{a}}$ MISA DE HAYDN

Capitulo 5: Planteamiento de hipótesis de interpretación de la música de Joseph Haydn a través de las fuentes estudiadas (copias valencianas, edición "autorizada” de Colonia, y otras).

Capitulo 6: Conclusiones.

Capitulo 7: Bibliografía.

Anexos:

Tablas cronológicas de situación.

Partituras y partichelas localizadas en los principales archivos musicales eclesiásticos de la Comunidad Valenciana con obras de Joseph Haydn:

01. Domine Deus salutis meae (Real Colegio-Seminario de Corpus Christi).

02. Cuartetos Op. 17 (Catedral de Orihuela).

03. Misa en Mi bemol Mayor, en honor de la Santísima Virgen María «Gran Misa para solo de órgano» (Real Colegio-Seminario de Corpus Christi; Catedral de Segorbe; y Catedral de Orihuela). 


\section{TESIS DOCTORALES}

04. Stabat Mater (Catedral de Valencia; Catedral de Segorbe; y Catedral de Orihuela).

05. O Jesu te invocamus (Real Colegio-Seminario de Corpus Christi).

06. Salve Regina en Sol menor (Real Colegio-Seminario de Corpus Christi).

07. Ens aeternum attende votis (Real Colegio-Seminario de Corpus Christi).

08. Misa breve a San Juan de Dios «Pequeña Misa para solo de órgano» (Catedral de Valencia).

09. Misa Cellensis compuesta para el señor Liebe de Kreutzner «Misa de Mariazell» (Catedral de Valencia; y Real Colegio-Seminario de Corpus Christi).

10. Las siete últimas palabras de nuestro Salvador en la Cruz (Catedral de Valencia; y Real Colegio-Seminario de Corpus Christi).

11. Misa en tiempos de guerra «Misa del timbal» (Catedral de Orihuela).

12. Ave Maria (Catedral de Valencia).

13. Insanae et vanae curae (Real Colegio-Seminario de Corpus Christi).

14. Misa en tiempos de miedo y necesidad «Misa Nelson» (Catedral de Valencia).

15. Te Deum para la emperatriz María Teresa (Real Colegio-Seminario de Corpus Christi).

16. Misa de La Creación (Real Colegio-Seminario de Corpus Christi).

17. Sancta Maria (Catedral de Valencia).

18. Ave verum (Catedral de Valencia).

19. Sanctus y Benedictus extraído de la $10^{a}$. Misa de HAYDN 1780. (Real ColegioSeminario de Corpus Christi). 